\title{
Management of Urethral Obstruction in a Cat with Epidural Sacrococcygeal Anesthesia Guided by Electrical Neurostimulation
}

\author{
Simone Marques Caramalac $\oplus_{\odot}$, Bets-Saba Naate Naumann Cerqueira Leite ${ }_{\odot}$, Silvana Marques Caramalac, \\ Fabrício de Oliveira Frazílio \& Mariana Isa Poci Palumbo
}

\begin{abstract}
Background: The treatment for urethral obstruction in cats consists of catheterization, and for this, the cat must be sedated or anesthetized. Sacococcygeal epidural block has the advantage of being close to receptors related to nociception located in the spinal cord and it is safer because it represents lower risk of spinal cord injury or inadvertent application in the subarachnoid space, when compared to the lumbosacral epidural. Nerve stimulation through the neurolocator to identify the epidural space increases the accuracy of this technique. Thus, the objective is to report a case of epidural anesthesia with a sacrococcygeal approach guided by neurostimulation in a cat with urethral obstruction.

Case: A 4-year-old male Siamese cat, weighing $4 \mathrm{~kg}$, was referred to the veterinary care with a history of apathy and anorexia for 2 days. From the physical exam, the clinical diagnosis of urethral obstruction was made, and to desobstruction, we chose to perform sacrococcygeal epidural block. Initially, the patient was anesthetized with propofol (4 mg/kg) and midazolam $(0.3 \mathrm{mg} / \mathrm{kg})$. To perform the anesthetic block, the cat was placed in sternal decubitus with the hind limbs extended cranially to perform sacrococcygeal epidural block. The positive pole (cathode) was connected to the skin of the right inguinal region at the caudal aspect of the thigh and the neurostimulator was turned on and adjusted to $0.7 \mathrm{~mA}$ of stimulating current intensity, $0.1 \mathrm{~ms}$ duration and $1 \mathrm{~Hz}$ frequency. The needle for electrical neurolocation was introduced in the dorsal midline, perpendicular to the skin surface, between the spinous processes of S3-Cd1 in the skin. The exact injection point was obtained observed by the muscular response of the middle and distal third of the animal's tail with the neurostimulator adjusted to $0.3 \mathrm{~mA}$ of intensity, in the same duration and frequency as before. The total volume of $0.9 \mathrm{~mL}$ $(0.22 \mathrm{~mL} / \mathrm{kg})$ of solution containing the combination of $0.6 \mathrm{~mL}$ of $0.75 \%$ levobupivacaine and $0.3 \mathrm{~mL}$ of $2 \%$ lidocaine was injected. The success of the block was confirmed by the loss of reflexes of the pelvic limbs and anal sphincter $10 \mathrm{~min}$ after the administration of the anesthetic solution.

Discussion: In this case, the use of the neurolocator helped to perform an effective sacrococcygeal block, allowing urethral catheterization without the addition of other analgesic agents. This technique desensitizes and relaxes muscles in the regions of the perineum, anus, distal colon and penis, being useful for performing urethral catheterization. The use of smaller anaesthetic volumes to perform sacrococcygeal block makes it possible to achieve a more localized anesthesia, without affecting the motor function of the pelvic limbs. However, in our report, using a combination of levobupivacaine and lidocaine, the pelvic limb block was also verified despite the low volume applied. A hypothesis that could justify the different responses in relation to the pelvic limb block compared to other studies would be due to the different physicalchemical properties of the drugs used. Lidocaine is known to be less fat-soluble than bupivacaine, so it tends to spread more through the epidural space, in order to result in more extensive blocks. The use of a neurostimulator using a fixed electric current of $0.7 \mathrm{~mA}$, pulse $0.1 \mathrm{~ms}$ and a frequency of $1 \mathrm{~Hz}$ allowed the correct identification of the needle position for the application of the anesthetic.
\end{abstract}

Keywords: local block, nerve stimulation, levobupivacaine, lidocaine. 


\section{INTRODUCTION}

Urethral obstruction is a common emergency condition in male cats, where the main goal of treatment is to reestablish the urinary flow as soon as possible. The treatment consists of urethral catheterization, and for this, the cat must be sedated or anesthetized. Local blocks are an alternative for relaxation and analgesia of the urethral region, which are essential for achieving a more comfortable and safe procedure [11].

Sacococcygeal epidural block has the advantage of being close to receptors related to nociception located in the spinal cord, enabling the drugs reduction doses, more potent analgesia and less side effects when compared to systemic administration [4]. In addition, it is safer because it represents lower risk of spinal cord injury or inadvertent application in the subarachnoid space, when compared to the lumbosacral epidural. Nerve stimulation through the neurolocator to identify the epidural space increases the accuracy of this technique, which is more predictable and less dependent on the operator [9]. Thus, the objective is to report a case of epidural anesthesia with a sacrococcygeal approach guided by neurostimulation in a cat with urethral obstruction.

\section{CASE}

A 4-year-old male Siamese cat, weighing $4 \mathrm{~kg}$, was brought to veterinary care with a history of apathy and anorexia for 2 days. On physical exam, an increase in abdominal volume was noted, with distension and stiffness of the urinary bladder, and it was not possible to establish urine flow through manual bladder massage. The animal was depressed, with $6 \%$ dehydration, presenting $180 \mathrm{bpm}$ heart rate associated with normal sinus rhythm, pink mucous membranes, two seconds of capillary refill time, normothermic, respiratory rate of $43 \mathrm{mpm}$ and systolic blood pressure $140 \mathrm{mmHg}$.

From the clinical diagnosis of urethral obstruction, the patient was anesthetized with propofol ${ }^{1}$ [Propovan ${ }^{\circledR}-2 \mathrm{mg} / \mathrm{kg}$, i.v.] and midazolam ${ }^{1}$ [Dormire ${ }^{\circledR}$ - $0.3 \mathrm{mg} / \mathrm{kg}$, i.v.], and the parameters heart rate (HR), respiratory rate (RR), and systolic blood pressure (SBP) [non-invasive through doppler ${ }^{2}$ - Medmega ${ }^{\circledR}$ DV 610V] were monitored throughout the anesthetic procedure.

To perform the anesthetic block, the cat was placed in sternal decubitus with the hind limbs extended cranially to perform sacrococcygeal epidural block with the aid of a neurostimulator ${ }^{3}$ [Neurolocalizador DL250]. The region corresponding to the puncture site was trichotomized and antisepsis was performed. The sacrococcygeal joint was identified through the palpation of its respective spinous processes and the mobility of the first coccygeal vertebra. Sterile compresses were placed around the puncture site and then the positive pole (cathode) was connected to the skin of the right inguinal region at the caudal aspect of the thigh. The needle extension line was filled with anesthetic solution and the neurostimulator was turned on and adjusted to $0.7 \mathrm{~mA}$ of stimulating current intensity, $0.1 \mathrm{~ms}$ duration and $1 \mathrm{~Hz}$ frequency (Figure 1). The needle for electrical neurolocation was introduced in the dorsal midline, perpendicular to the skin surface, between the spinous processes of S3-Cd1 in the skin (Figure 2). The needle was introduced slowly through the epaxial musculature until it was placed on the yellow ligament, as evidenced by the presence of resistance to the needle progression. The exact injection point was obtained after crossing the yellow ligament, observed by the muscular response of the middle and distal third of the animal's tail with the neurostimulator adjusted to $0.3 \mathrm{~mA}$ of intensity, in the same duration and frequency as before. After the confirmation of absence of blood and cerebrospinal fluid reflux, the total volume of $0.9 \mathrm{~mL}(0.22 \mathrm{~mL} / \mathrm{kg})$ of solution containing the combination of $0.6 \mathrm{ml}$ of levobupivacaine ${ }^{1}$ [Novabupi ${ }^{\circledR} 0.75 \%-0.15 \mathrm{~mL} / \mathrm{kg}$ ] and $0.3 \mathrm{~mL}$ of lidocaine ${ }^{4}$ [Cloridrato de lidocaína $2 \%$ - $0.075 \mathrm{~mL} / \mathrm{kg}$ ] was injected.

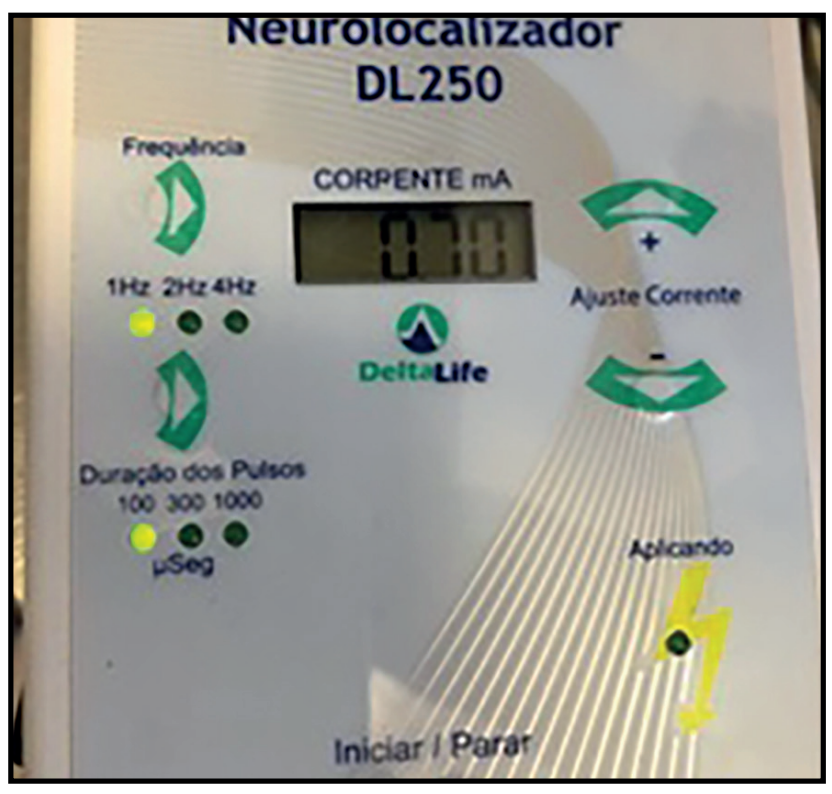

Figure 1. Adjustment of the neurostimulator for electric current in the intensity of $0.7 \mathrm{~mA}$, frequency $1 \mathrm{~Hz}$ and $0.1 \mathrm{~ms}$ duration. 


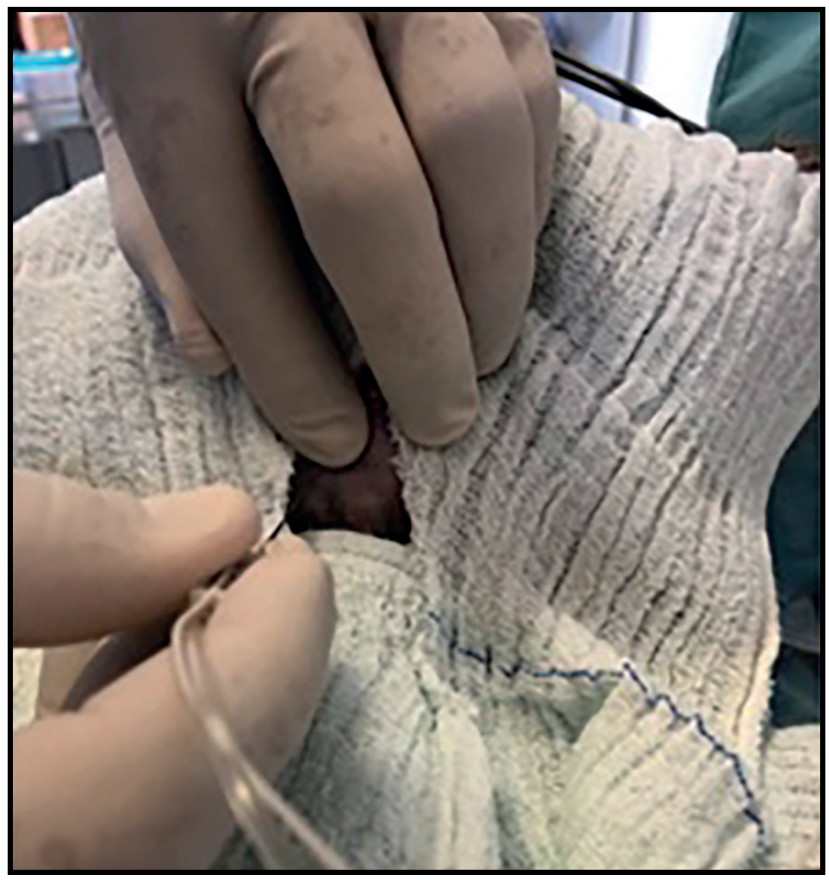

Figure 2. Moment of introduction of the needle into the dorsal midline, perpendicular to the skin surface at the sacrococcygeal site.

The success of the block was confirmed by the loss of reflexes of the pelvic limbs and anal sphincter 10 min after the administration of the anesthetic solution. The cardiorespiratory parameters maintained stable during the procedure, with means of heart rate $138 \mathrm{bpm}$, respiratory rate $30 \mathrm{mpm}$ and systolic blood pressure $120 \mathrm{mmHg}$. Thus, it was possible to easily insert a sterile urethral catheter number 4 and it was not necessary to administer more general anesthetics.

\section{DISCUSSION}

In this case, the use of the neurolocator helped to perform an effective sacrococcygeal block, allowing urethral catheterization without the addition of other analgesic agents. This technique is characterized by desensitizing and relaxing the muscles in the regions of the perineum, anus, distal colon, and penis, thus being useful for performing procedures in these places, such as urethral catheterization [5].

There are still few studies that establish the volumes used in the sacrococcygeal epidural in cats [3]. The use of smaller volumes makes it possible to perform a more localized block, without affecting the motor function of the pelvic limbs, leading to a faster and smoother anesthetic recovery [6]. In dogs, sacral plexus block using $0.075 \mathrm{~mL} / \mathrm{kg}$ of ropivacaine $0.75 \%$ resulted in no involvement of the pelvic limbs in the block [6]. Using bupivacaine $0.5 \%$ (0.2 and $0.4 \mathrm{~mL} / \mathrm{kg}$ ) to perform sacrococcygeal block in cats with neurostimulator, it was obtained tail, perineum and pelvic limb block [3]. According to the authors, motor and sensory blockade of the limbs occurred only in those who received a greater volume of the anesthetic. It was also verified pelvic limb block, using $0.3 \mathrm{~mL} / \mathrm{kg}$ of bupivacaine $0.5 \%$ [9]. However, in our report, using the combination of levobupivacaine and lidocaine, totaling the volume of $0.22 \mathrm{~mL} / \mathrm{kg}$, the pelvic limb block was also verified despite the low volume applied. A hypothesis that could justify the different responses in relation to the pelvic limb block compared to other studies would be due to the different physical-chemical properties of the drugs used. Lidocaine used in association in this report, as it is less fat-soluble than bupivacaine, tends to spread more through the epidural space, in order to result in more extensive blocks [1]. Another hypothesis for the different pelvic limb block responses would be due to the variability of the technique performed, since faster applications in the epidural space result in greater ascendancy of the drug [10].

The use of anesthesia with a multimodal approach increases safety, since it makes it possible to use lower doses and thus reduce the occurrence of complications, such as hypoventilation and hypotension [11]. In the present case, the sacrococcygeal local blocking technique made it possible to numb the perineal region with minimal interference in cardiovascular parameters. Depending on the time of evolution and intensity of clinical signs, cats with urethral obstruction have hydroelectrolytic disorders that increase the anesthetic risk, such as dehydration and hyperkalaemia [2]. Despite this, anesthetic interventions are necessary and must be promptly performed, since urethral desobstruction is the only effective treatment for restoring homeostasis.

In addition, sacrococcygeal epidural block has the advantage of safety regarding the possibility of injury to nervous tissue, since the medullary cone in felines reaches the first sacral vertebra, thus having less chance of neurological damage $[7,8]$. The use of the neurolocalizer further increases the safety of the block, with the motor response obtained after puncture of the interconnected ligament with a positive predictive value of $95.8 \%$ [9].

Although, in the present case, the same electrical current $(0.7 \mathrm{~mA})$ and pulse $(0.1 \mathrm{~ms})$ were used, the frequency used in this case $(1 \mathrm{~Hz})$ was lower than that 
used in previous studies [3,9], who used $2 \mathrm{~Hz}$. Despite this, the use of this frequency still allowed the correct location of the sacrococcygeal epidural space.

The sacrococcygeal epidural block consists of an effective anesthetic technique for blocking the penile region, allowing the performance of urethral catheterization of obstructed cats. The use of a neurostimulator using a fixed electric current of $0.7 \mathrm{~mA}$, pulse $0.1 \mathrm{~ms}$ and a frequency of $1 \mathrm{~Hz}$ allowed the correct identification of the needle position for the application of the anesthetic. In addition, the association of levobupivacaine with lidocaine also led to pelvic limb block, despite the low volume administered.

\section{MANUFACTURERS}

${ }^{1}$ Cristália Produtos Químicos Farmacêuticos Ltda. Itapira, SP, Brazil.

${ }^{2}$ Medmega Industria de Equipamentos Médicos Ltda. Franca, SP, Brazil.

${ }^{3}$ DeltaLife Tecnologia e Serviços da Vida. São José dos Campos, SP, Brazil.

${ }^{4}$ Hipolabor Farmacêutica Ltda. Belo Horizonte, MG, Brazil.

Acknowledgements. This study was financed in part by the Coordenação de Aperfeiçoamento de Pessoal de Nível Superior - Brasil (CAPES) - Finance Code 001.

Declaration of interest. The authors report no conflicts of interest. The authors alone are responsible for the content and writing of the paper.

\section{REFERENCES}

1 Bernards C.M. 2004. Recent insights into the pharmacokinetics of spinal opioids and the relevance to opioid selection. Current Opinion in Anesthesiology. 17(5): 441-447. DOI: 10.1097/00001503-200410000-00015.

2 Cooper E.S. 2015. Controversies in the management of feline urethral obstruction. Journal of Veterinary Emergency and Critical Care. 25(1): 130-137. DOI: 10.1111/vec.12278.

3 Costa G.A. 2015. Avaliação sensitiva e motora de gatos submetidos à anestesia peridural guiada por neuroestimulação pela abordagem sacrococcígea com diferentes volumes de bupivacaína 0,5\%. 112f. Rio de Janeiro, RJ. Dissertação (Mestrado em Medicina Veterinária) - Curso de Pós-Graduação, Universidade Federal Rural do Rio de Janeiro.

4 Garcia-Pereira F. 2018. Epidural anesthesia and analgesia in small animal practice: an update. The Veterinary Journal. 242: 24-32. DOI: $10.1016 /$ j.tvj1.2018.09.007

5 Garcia-Pereira F.L., Hauptman J., Shih A.C., Laird S.E. \& Pease A. 2010. Evaluation of electric neurostimulation to confirm correct placement of lumbosacral epidural injections in dogs. American Journal of Veterinary Research. 71(2): 157-160. DOI: 10.2460/ajvr.71.2.157

6 Gregori T., Viscasillas J. \& Benigni L. 2014. Ultrasonographic anatomy of the sacrococcygeal region and ultrasound-guided epidural injection at the sacrococcygeal space in dogs. Veterinary Record. 175(3): 68-68. DOI: 10.1136/ vr.102453

7 Jones R. 2001. Epidural Analgesia in the Dog and Cat. The Veterinary Journal. 61(2): 123-131. DOI:10.1053/ tvj1.2000.0528

8 Otero P.E. 2013. Anestesia locorregional do neuroeixo. In: Klaumann P.R. \& Otero P.E. (Eds). Anestesia Locorregional em Pequenos Animais. São Paulo: Roca, pp.135-176.

9 Otero P.E., Verdier N., Zaccagnini A.S., Fuensalida S.E., Tarragona L. \& Portela D.A. 2015. The use of a nerve stimulation test to confirm sacrococcygeal epidural needle placement in cats. Veterinary Anaesthesia and Analgesia. 42(1): 115-118. DOI:10.1111/vaa.12173

10 Sen O., Donmez N.F., Ornek D., Kalayci D., Arslan M. \& Dikmen B. 2012. Efeitos da inclinação de agulha peridural e diferentes velocidades de injeção na distribuição de anestesia peridural. Revista Brasileira de Anestesiologia. 62(6): 857-862. DOI: 10.1590/S0034-70942012000600010

11 Skarda R.T. \& Tranquilli W.J. 2013. Anestésicos locais. In: Tranquilli W.J., Thurmon J.C. \& Grimm K.A. (Eds). Lumb \& Jones' Anestesiologia e Analgesia Veterinária. São Paulo: Roca, pp.428-454. 